\title{
Increasing wealth and increasing instability: The role of collateral*
}

\author{
Chung Yi Tse \\ University of Hong Kong
}

\author{
Charles Kai Yui Leung \\ Chinese University of Hong Kong
}

April 19, 2001

*Acknowledgment: The authors are grateful to the comments from E. Kwan Choi, Michael Devereux, Kar-Yiu Wong, seminar participants of the Asian Crisis: the Economics Front conference (1998, Seattle) and last but not least an anonymous referee. Tse gratefully acknowledges financial support from HKU URC grants 7157/98H. Correspondence: Tse, School of Economics and Finance, University of Hong Kong, Pokfulam Road, Hong Kong, (Phone) 852-2859-1035, (Fax) 2548-1152, (E-mail) tsechung@econ.hku.hk; Leung, Department of Economics, Chinese University of Hong Kong, Shatin, Hong Kong; (Phone) 852-2609-7158; (Fax) 2603-5805; (E-mail) charlesl@cuhk.edu.hk. 


\begin{abstract}
History repeats the same story about financial crises every few years. High growth in domestic credit almost always guarantee the outbreak of a crisis. In normal times, growth in credit is generally associated with faster long run growth, however, as financial intermediation improves the efficiency of channelling capital to productive investment. We present an endogenous growth model to reconcile the two seemingly contradictory stylized facts. Given that there is a significant fixed cost for joining financial intermediation, households are excluded from the credit market at low levels of development, thereby insulated from the disturbance of the financial market. When enough wealth has been accumulated to cross the threshold, they take advantage of international borrowing, but become leveraged and vulnerable to shocks in the world capital market.

JEL Classifications: E32, O16, O41, O53.

Keywords: endogenous growth, liquidity constraint, finance and development, Asian crisis.
\end{abstract}




\section{INTRODUCTION}

Central to the debate in economic crises is the question : are crises purely random? The answer from an empirical point is a definite negative. Researchers have identified several robust indicators for forecasting crises. ${ }^{1}$ Among others, "unusual growth" in output and credit is highly correlated with the outbreak of economic crises. This finding is in line with the recent development in business cycles research. Specifically, Kiyotaki and Moore (1997, KM hereafter) ${ }^{2}$ show that when firms engage in leverage borrowing, tiny productivity shocks can lead to huge fluctuations in output through the induced fluctuations in the values of collateral. Extending the intuition to countries engaging in leverage international borrowing, it is none too surprising that they too would be extremely vulnerable to shocks in the world capital market. A rough and ready confirmation of this view can be found by comparing the experiences of Hong Kong and Singapore which have relatively open capital markets and Taiwan which has a relatively closed capital market in the Asian crisis. Not unexpectedly, the more open Hong Kong and Singapore economies suffer substantially greater output declines than the relatively closed Taiwan. ${ }^{3}$

However, the idea that international lending could lead to a sharp drop in output is apparently at odds with the long tradition in development economics about the important role of finance in promoting growth and development. In a well known study, King and Levine (1993) establish a strong and robust link between financial development and long run growth in a large cross-section of countries. ${ }^{4}$ In fact, before the outbreak of the Asian crisis, many economists believed that having access to the international capital markets is a key element of explaining the "Asian Miracle." International capital flows also feature prominently in theoretical analysis. One only needs to recall that unrestricted international borrowing enables a country to attain convergence to its steady state output level instantaneously in the neoclassical growth model. ${ }^{5}$ More recently, Greenwood and

\footnotetext{
${ }^{1}$ For instance, see Frankel and Rose (1996), Otker and Pazarbasioglu (1997) and Wong (1998).

${ }^{2}$ See also Kiyotaki (1998).

${ }^{3}$ See Wong (1998) for details.

${ }^{4}$ See Levine (1997), Levine and Zervos (1998) for more evidence and a survey of the literature.

${ }^{5}$ See Turnovsky (1997). For a dissenting view that foreign capital inflow may inhibit growth, see Boyd
} 
Jovanovic (1990, GJ hereafter) show how the development of financial market can improve economic growth. ${ }^{6}$

In all, a theory to reconcile the crises literature and the finance and growth literature is warranted. This is what we will do in this paper. We argue that the two literature are in fact describing the two sides of the same coin. Here is the idea. Entry to the international capital market entails a significant entry cost. Accordingly, countries in the early stage of development would be unable to take advantage of international borrowing. They are insulated from shocks in the world capital market though. Entry to the world capital market takes place when a country has accumulated sufficient wealth. Thereafter, international leverage borrowing enables the country to attain a higher investment rate and faster growth, while in the meantime, it becomes vulnerable to shocks in the world capital market.

The notion of endogenous financial development and the presence of a significant entry cost to financial intermediation are not novel ideas. They are first formalized in GJ and our contribution is to add the collateral constraint introduced by KM to study the complicated interactions between financial development, leverage borrowing and fluctuations. ${ }^{7}$

The basic structure of our analysis is from the $A k$ endogenous growth model of Rebelo (1991). ${ }^{8}$ We add land as a factor of production and the possibility of international borrowing at an interest rate below the domestic user cost of capital. Following KM, we assume that the representative household in the domestic economy may only borrow up the value of the collateral, which we take as the stock of physical capital and the endogenously determined value of land. This imposes an upper bound to borrowing which and Smith (1997).

${ }^{6}$ See also Bencivenga and Smith (1991).

${ }^{7}$ There is another difference between GJ and our paper. GJ model access to financial intermediation as gaining access to a investment technology that yields a higher return to investment. Ours has a more detailed microeconomic foundation in that we model access to financial intermediation as the access to borrowing and lending at the world interest rate.

${ }^{8}$ While we restrict the formal analysis within a linear growth framework, the idea should apply in a much boarder class of growth model. In fact, Long and Wong (1997) show that there is a class of growth model whose reduced form is identical to AK model. 
would otherwise be absent in a model with constant returns to scale. ${ }^{9}$ By construction, the poorest countries in the model would not be able to borrow internationally. They grow slowly but they are insulated from shocks in the world capital market. On the other hand, the faster growing countries that have borrowed internationally could experience dramatic fluctuations in output, physical capital and asset price from tiny shocks to the world interest rate. Land price plays a special role in amplifying the shocks. We take that land and physical capital are complementary in production. There is a powerful multiplier process when land is used as collateral in leverage borrowing. At higher land price, more loans can be obtained. The resulting higher investment in physical capital will further boost the marginal productivity and henceforth the price of land. And then the higher land price will support even more leverage borrowing, ad infinitum. A tiny positive interest rate shock sets the process in reverse and would eventually result in dramatic declines in land price, physical capital and output.

Although the basic model is essentially $A k$ in structure, the dynamics are non-trivial. We find that in the transition to entering international borrowing, output and physical capital grow at an increasing rate. More interestingly, under some parameter restrictions, land price could grow at a faster rate than output and physical capital in a perfect foresight equilibrium that is free of any elements of speculative bubbles.

This paper is among a growing literature on explaining the Asian crisis. Devereux (1998), on comparing the monetary institutions between Hong Kong and Singapore, explains how different exchange rate regimes can affect the ways economies respond to external shocks. Lee and Kim (1998) argue that government subsidies indirectly create a property market bubble that deepens the crisis. We abstract from these considerations and instead focus on the endogenous change in vulnerability of a small open economy to fluctuations in the world capital market.

The next section presents the model of international leverage borrowing and endogenous entry to the world capital market. Section 3 studies the dynamics of output and asset

\footnotetext{
${ }^{9}$ In constrast, Turnovsky and Chattopadhyay (1998) do not impose an explicit bound on international borrowing but instead assume an upward sloping supply of funds schedule.
} 
price. Section 4 analyzes the response of a borrowing economy to shocks to the world interest rate. Section 5 concludes.

\section{MODEL}

\section{A. Basics}

We study a model of a small open economy populated by a continuum of identical households with total measure equal 1 . Time is continuous and the horizon is infinite. The discounted lifetime utility of the representative household at time 0 is

$$
U=\int_{0}^{\infty} e^{-\rho \tau} \ln c(\tau) d \tau
$$

where $\rho$ is the subjective rate of time preference and $c(\tau)$ is consumption at time $\tau$. There are three types of goods: output, physical capital and land. There is a world market for output and for physical capital, whose prices are both equal 1. Land is not accumulable and its domestic supply is normalized to 1 . Let $k(\tau)$ and $l(\tau)$ be capital and land input respectively. The household-producer has access to the production function

$$
y(\tau)=A k(\tau) l(\tau)^{\alpha}
$$

where $\alpha \in(0,1)$. We assume that each household-producer may hire no more than 1 unit of land in production at each point in time, so that a competitive equilibrium can be sustained even though (1) exhibits increasing returns to the two inputs. ${ }^{10}$

At time 0 , the household has an endowment of $k(0)=k_{0}$ and $l(0)=1$. Let $\delta$ be the rate at which capital depreciates, $x_{k}(\tau)$ investment in physical capital, $x_{l}(\tau)$ investment in land and $q(\tau)$ the unit price of land in terms of the output good. The household's holding of physical capital and land evolves according to

$$
\dot{k}(\tau)=x_{k}(\tau)-\delta k(\tau)
$$

\footnotetext{
${ }^{10}$ Alternatively, we can assume that the marginal product of land is 0 for $l>1$, that is $y=A k$ for $l>1$. Since land is not accumulable and with the domestic supply fixed at 1 , the assumption does not affect the generality of the results in the paper, but merely serves to ensure the existence of competitive equilibrium.
} 


$$
i(\tau)=\frac{x_{l}(\tau)}{q(\tau)}
$$

Notice that the technology is essentially Ak because land is fixed in supply. If not for its role as collateral to be explained in the next section, its presence in the production function is spurious and could have been subsumed in the productivity parameter $A$.

Throughout the analysis that follows, we assume that:

$$
\text { (A1) } A>\rho+\delta \text {. }
$$

The assumption is a standard one that allows for positive endogenous growth for a closed economy with Ak technology and logarithmic preference.

\section{B. Finance and Development}

The country faces a world interest rate $r$. However, access to international borrowing is not unrestricted. In practice, the market for lending and borrowing, especially one that crosses national borders, is plagued by a whole array of informational problems that makes it difficult for individuals to locate suitable trading partners, and for creditors to monitor their investment. Financial intermediaries arise to help match lenders and borrowers and monitor investment on behalf of their clients, among the other functions they perform. These services are surely not available for free. More importantly, domestic firms may have to alter their accounting conventions and other practices to convince foreign as well as domestic financial intermediaries that they represent prudent investment. We model the resources that the domestic household-producer would have to spend to gain access to the market as the payment of a one time fixed cost equal to $\theta$ units of capital. ${ }^{11}$

With a Ak technology, the net marginal product of capital is constant at $A-\delta .^{12}$ If the world interest rate $r>A-\delta$, the household is better off shutting down domestic production and invests all resources abroad. Conversely, if $r<A-\delta$, domestic production yields higher returns than investment abroad. Since our analysis is about growth and

\footnotetext{
${ }^{11}$ We refer the readers to the discussion in GJ where this assumption is first introduced in models of finance and development.

${ }^{12}$ More precisely, the net marginal product of physical capital is $A l^{\alpha}-\delta$. With the supply of land fixed at 1 , it reduces $A-\delta$.
} 
instability from international borrowing for an indebted developing country, the latter case is more relevant for our purpose.

(A2) $A>r+\delta$.

Under the above assumption, the household would like to borrow the maximum possible by virtue of its access to a constant returns technology. As in KM, we assume that the maximum the household can borrow is constrained by the value of collateral that the household can put up.

Nevertheless, the household may not want to enter the world capital market to borrow at time 0 even if the world interest rate is below the net marginal product of capital. At low levels of wealth, the sacrifice it may have to make to join intermediation (the payment of $\theta$ ) will outweigh the benefit. It may be optimum for the household to wait for a finite period of time to accumulate enough wealth before entering the world capital market to engage in leverage borrowing.

In the next section, we will describe the household's problem and the equilibrium for an economy that has already sunk $\theta$ to gain access to international leverage borrowing. Then we will backtrack to describe the household's problem and the equilibrium before doing so.

\section{Equilibrium with international borrowing}

\section{Leverage Borrowing.-}

Let $T$ be the time the household joins international leverage borrowing. Say its capital holding at $T$ after paying the entry cost $\theta$ is equal to some $k(T)=k_{T}$. In equilibrium, its holding of land must equal 1. Denote $b(\tau)$ as its borrowing at $\tau>T$. The amount of debt at any moment is constrained by the values of the household's holding of physical capital and land to be used as collateral: ${ }^{13}$

$$
(1+r) b(\tau) \leq(1-\delta) k(\tau)+q(\tau) l(\tau)
$$

\footnotetext{
${ }^{13}$ We follow KM's assumption in justifying why creditors would not be willing to lend more than the value of the borrowers' tradeable assets. See footnote 8 of KM.
} 
In equilibrium, $l(\tau)$ will equal 1 . But at this stage, it is useful to state the constraint in the general form. The borrowing constraint will be binding if (A2) holds:

$$
b(\tau)=\frac{1}{1+r}[(1-\delta) k(\tau)+q(\tau) l(\tau)]
$$

International borrowing allows the household to amass more resources in production than what it actually owns. Denote $e(\tau)$ as the household's equity. We have the identity:

$$
e(\tau)=k(\tau)+q(\tau) l(\tau)-b(\tau)
$$

Applying (5)

$$
e(\tau)=\frac{r+\delta}{1+r} k(\tau)+\frac{r}{1+r} q(\tau) l(\tau)
$$

The above captures the notion of leverage borrowing in that the household's equity is only a fraction of the asset of the firm.

At time $T$, the instant the household enters the world capital market, it does not yet owe any debt. Indeed, it owns all the capital stock and land that the firm possesses then

$$
e(T)=k(T)+q(T) l(T)=k_{T}+q(T)
$$

Furthermore, the path for $e$ must be smooth throughout as the household cannot accumulate any physical capital on its own in an interval of zero length ${ }^{14}$ nor can there be a jump in the price of land for otherwise there exists unexploited arbitrage opportunity. This implies $e^{+}(T)=e(T)$ where the former denotes equity at an instant after $T$. All said, at the instant after $T$, the equity-asset relationship in (6) is

$$
k_{T}+q^{+}(T)=\frac{r+\delta}{1+r} k^{+}(T)+\frac{r}{1+r} q^{+}(T)
$$

where we have made use of the facts that the supply of land is fixed at 1 and its price cannot experience any discontinuity so that $q(T)=q^{+}(T)$. Simplifying

$$
k^{+}(T)=\frac{1+r}{r+\delta} k_{T}+\frac{1}{r+\delta} q^{+}(T)
$$

Since $\delta<1$, the above implies that $k^{+}(T)>k(T)=k_{T}$. There will be a discrete jump in $k$ the moment after entry to the world capital market as the capital stock that the

\footnotetext{
${ }^{14}$ It may nevertheless do so through borrowing.
} 
household possesses is jack up via international borrowing. The relationship in (7) has a very intuitive interpretation. On the left side is the quantity of physical capital the household may be able to mass, which is a multiple of its initial capital holding $k_{T}$ and the value of its land holding $q$, the sum of which is the household's equity used as the collateral in the leverage borrowing. The exact value of the multiplier is endogenous because the value of land $q$, whose determination will be dealt with in the following, in turn depends on land's marginal productivity which is a function of the stock of physical capital with our assumption of physical capital-land complementarity.

It should be emphasized that the above analysis is based entirely from the accounting identity that equity is equal to asset minus debt, rather than from any maximizing behaviors on the part of the household at $T$. It would hold so long as the household-producer chooses to engage in maximum leverage borrowing.

\section{The agent's maximization problem.-}

At any time $\tau>T$, the receipts of the household consist of the output from production and any increase in borrowing. Its expenditure includes consumption and investment spending, as well as interest payment. This yields the budget constraint

$$
y(\tau)+\dot{b}(\tau)=c(\tau)+x_{k}(\tau)+x_{l}(\tau)+r b(\tau)
$$

that holds at each $\tau>T$. Using (5), (2), (3) and (1), the budget constraint expands into

$$
\begin{aligned}
c(\tau)= & A k(\tau) l(\tau)^{\alpha}+\frac{1}{1+r}\left\{(1-\delta)\left(x_{k}(\tau)-\delta k(\tau)\right)+\dot{q}(\tau) l(\tau)+x_{l}(\tau)\right\} \\
& -x_{k}(\tau)-x_{l}(\tau)-\frac{r}{1+r}\{(1-\delta) k(\tau)+q(\tau) l(\tau)\}
\end{aligned}
$$

The household's problem is

$$
V_{I}\left(k_{T}\right)=\max \left\{\int_{T}^{\infty} e^{-(\tau-T) \rho} \ln c(\tau) d \tau\right\}
$$

with $c(\tau)$ given in (9) subject to (2) and (3) and the initial conditions:

$$
\begin{aligned}
k^{+}(T) & =\frac{1+r}{r+\delta} k_{T}+\frac{1}{r+\delta} q^{+}(T), \\
l(T) & =1
\end{aligned}
$$


Note that the household takes as given the path for $q(\tau)$ in $(10)$ whose value will be pinned down in equilibrium when the demand for and the supply of land are equated. In solving (10), it is not necessary to impose a no-ponzi scheme condition on borrowing since the debt is assumed to be perfectly collateralized at each moment of time.

For the equilibrium to be well-defined, the following two additional assumptions are called for.

$$
\begin{array}{ll}
\text { (A3a) } & \frac{1+\rho}{1+\alpha}(r+\delta)>A, \\
\text { (A3b) } & r>\rho>\alpha .
\end{array}
$$

We summarize the characterization of the equilibrium in the following proposition the proof of which, as well as the proofs of all propositions to follow, is relegated to the appendix.

\section{Proposition 1}

(a) Beginning with $k(T)=k_{T}$ units of physical capital, the onset of leverage borrowing permits the household to amass a discretely higher quantity of physical capital than what it holds at the entry date.

$$
k^{+}(T)=\frac{1+r}{r+\delta} \frac{(1+\rho)(r+\delta)-A}{(1+\rho)(r+\delta)-A(1+\alpha)} k_{T}
$$

(b) Capital, output and consumption grow at the common constant rate

$$
\gamma=\frac{1+r}{r+\delta} A-1-\rho
$$

(c) Consumption is related to physical capital at each $\tau>T$ according to

$$
c(\tau)=\Phi_{1} k(\tau) \quad \text { where } \Phi_{1}=\frac{r+\delta}{1+r}\left(\rho+\alpha A\left[\frac{(A-r-\delta) r}{[(1+\rho)(r+\delta)-A]}-1\right]\right)
$$

whereas the relationship between consumption and the initial capital stock is governed by

$$
c(\tau)=\Phi_{2} k_{T} e^{\gamma(\tau-T)} \quad \text { where } \Phi_{2}=\Phi_{1} \frac{1+r}{r+\delta} \frac{(1+\rho)(r+\delta)-A}{(1+\rho)(r+\delta)-A(1+\alpha)} .
$$

(d) The price of land is proportional to the capital stock via

$$
q(\tau)=\frac{\alpha A(r+\delta)}{(1+\rho)(r+\delta)-A} k(\tau)
$$


The two assumptions in (A3) serve to ensure the positivity of $q$ and the ratio of consumption to physical capital in part (c). Part (d) implies that $q(\tau)$ is increasing in $A$ and $\alpha$. This is intuitive as an increase in either $A$ or $\alpha$ raise the marginal product of land. And then at $\alpha=0$, land has no value in production and hence $q(\tau)=0$.

In case the world interest rate is just equal to the net marginal product of capital, i.e. $r=A-\delta$, it can be verified from parts (b) and (c) that $c(\tau)=\rho k_{T} e^{\gamma^{a}(\tau-T)}$ where $\gamma^{a}=A-\delta-\rho$, which is the consumption path of the standard closed economy Ak model. This is because with $r=A-\delta$, the return from investing any borrowed resources is just sufficient to cover the interest payment and physical depreciation, and as a result the optimum consumption path is left unaffected.

Under (A2) that $r<A-\delta$, there are both a growth effect and a level effect. Beginning with $k(T)=k_{T}$, there will be a discrete jump in $k$ just after $T$. After the jump, the consumption-capital ratio is $\Phi_{1}$. Under most reasonable values for $r$ and $\delta, \Phi_{1}$ is strictly below $\rho$ which is the consumption-capital ratio in the closed economy Ak model. Hence, the optimum accumulation path with borrowing could result in lower consumption as a fraction of the capital stock. But the capital stock jumps to a higher level the moment after $T$. If $r<A-\delta$, it can be shown that $\Phi_{2}>\rho$ so that the jump would more than compensate for the reduction in the consumption-capital ratio, and consumption as a fraction of the initial capital stock is higher then. This is the level effect. Furthermore, under (A2) that $A>r+\delta, \gamma>\gamma^{a}$, the capital stock grows at a faster rate. This is the growth effect.

Finally, with consumption growing at a constant rate, we may evaluate (10) using parts (b) and (c) to yield

$$
V_{I}\left(k_{T}\right)=\frac{1}{\rho}\left(\ln k_{T}+\ln \Phi_{2}+\frac{\gamma}{\rho}\right) .
$$

relating discounted lifetime utility at $T$ as a function of initial capital stock $k_{T}$.

\section{Current account balance.-}

With constant growth, at each $\tau>T$, the net amount of resources made available from 
international borrowing $^{15}$

$$
\dot{b}-r b=b\left(\frac{\dot{b}}{b}-r\right)=b(\gamma-r)
$$

is either positive or negative throughout. If $\gamma<r$, the economy relinquishes resources to the outside world at each $\tau>T$. It is nevertheless better off if $A-\delta>r$ with international borrowing because the outflow of resources is more than compensated by the inflow at $\tau=T$. The current account is in deficit at $T$ but is in surplus thereafter. On the other hand, if $\gamma>r$, there is net inflow of resources into the economy at $T$ as well as at each moment thereafter. The current account is perpetually in the red.

Since the amount of debt grows at $\gamma$, the present value grows at $\gamma-r$. In case $\gamma<r$, the present value of debt asymptotes to 0 . This is usually thought to be the condition necessary for current account sustainability. ${ }^{16}$ On the other hand, if $\gamma>r$, the present value of debt grows without bounds. But with the debt perfectly collateralized by productive assets that grow at the same rate, the household cannot be considered as running a ponzi scheme. Intuitively, unlike a regular ponzi game, with the debt perfectly collateralized by productive assets, each and everyone of the foreign investors can recover their investment together with the promised interest payment any time by simply liquidating the asset if they so desire.

\section{Autarkic equilibrium}

Now we backtrack to the problem the household faces before having paid $\theta$ to gain access to international borrowing. Given the initial holding of physical capital and land: $k(0)=k_{0}$ and $l(0)=1$, it chooses investment at each $\tau$ and the timing of entry to the world capital market to maximize lifetime discounted utility.

$$
V\left(k_{0}\right)=\max \left\{\int_{0}^{T} e^{-\rho \tau} \ln c(\tau) d \tau+e^{-\rho T} V_{I}(k(T)-\theta)\right\} .
$$

\footnotetext{
${ }^{15}$ From (5), $b$ is proportional to the sum of $k$ and $q$. From (13), $q$ is proportional to $k$. Hence $b$ is proportional to $k$.

${ }^{16}$ See Obstfeld and Rogoff (1996, chapter 2).
} 
The maximization is over $x_{k}(\tau)$ and $x_{l}(\tau)$ for $\tau \leq T$ and the timing of entry $T$, subject to a budget constraint that neither allows borrowing nor lending:

$$
c(\tau)=A k(\tau)-x_{k}(\tau)-x_{l}(\tau)
$$

and the equations of motion for $k(\tau)$ and $l(\tau)$ in $(2)$ and (3) respectively. ${ }^{17}$

It is easiest to proceed by breaking up the problem into two parts. First define

$$
V_{a}\left(k_{0}, k^{*}, T\right)=\max _{x(\tau)}\left\{\int_{0}^{T} e^{-\rho \tau} \ln c(\tau) d \tau\right\}
$$

subject to the initial conditions, the budget constraint, and the equation of motions as specified above, as well as a terminal condition, $k(T)=k^{*}$. This gives the discounted utility before gaining access to international borrowing where the date of entry and the amount of capital to carry over are fixed respectively at some $T$ and $k^{*}$. The second step is to pick the optimal $T$ and $k^{*}$.

We present the key results of the first step in the following proposition.

Proposition 2 Fixing $T$ and $k^{*}$, solving (16) and imposing the equilibrium condition $l(\tau)=1$ yields:

(a) A constant growth rate of consumption at

$$
\gamma^{a}=A-\delta-\rho
$$

(b) The evolution of capital governed by the differential equation

$$
k(\tau)=\left(\frac{c(0)}{\rho}\right) e^{(A-\delta-\rho) \tau}+B e^{(A-\delta) \tau} .
$$

where the two constants $c(0)$ and $B$ are functions of $T$ and $k^{*}$ the exact expressions of which can be found in the appendix.

With consumption growing at a constant rate, we may evaluate the discounted utility from time 0 to $T$ to yield

$$
V_{a}\left(k_{0}, k^{*}, T\right)=\frac{1}{\rho}\left\{\left(1-e^{-\rho T}\right)\left[\ln c(0)+\frac{\gamma^{a}}{\rho}\right]-\gamma^{a} e^{-\rho T} T\right\} .
$$

\footnotetext{
${ }^{17}$ Notice that in the above, the investment decisions after $T$ are subsumed in $V_{I}($.$) .$
} 


\section{E. Entry to international capital market}

We now have all the ingredients necessary to solve for the optimum entry date and the capital stock to prepare for the transition, $T$ and $k^{*}$. To this end, add (18) to the discounted value of (14) to obtain discounted lifetime utility at time 0:

$$
V\left(k_{0}\right)=\max _{T, k^{*}}\left\{V_{a}\left(k_{0}, k^{*}, T\right)+e^{-\rho T} V_{I}\left(k^{*}-\theta\right)\right\} .
$$

Remember that the first term denotes discounted utility from time 0 up to some fixed $T$ with a fixed terminal capital stock $k(T)=k^{*}$. At time $T$, it enters the world capital market by paying the entry cost $\theta$. The second term denotes the discounted utility from $T$ onwards.

Proposition 3 The optimal choices of $T$ and $k^{*}$ are given respectively by

$$
\begin{gathered}
k^{*}=e^{(A-\delta-\rho) T} k_{0}+\left(1-e^{-\rho T}\right) \theta \\
\frac{k_{0} e^{(A-\delta) T}+\left(e^{\rho T}-1\right) \theta}{k_{0} e^{(A-\delta) T}-\theta} \leq \frac{\rho}{A-\delta} \ln \left(\frac{\Phi_{2}}{\rho}\right)+\frac{\gamma+\rho}{\gamma^{a}+\rho} .
\end{gathered}
$$

for $T \geq(A-\delta)^{-1} \ln \left(\theta / k_{0}\right)$.

The reason why only values of $T \geq \frac{1}{A-\delta} \ln \left(\frac{\theta}{k_{0}}\right)$ are admissible is that the maximum amount of physical capital that can be accumulated starting from $k(0)=k_{0}$ in an interval of length $T$ is $k_{0} e^{(A-\delta) T}$. If that amount is below $\theta$, there will simply not be enough to pay for the entry cost. It can be verified that the left side of (21) is decreasing in $T$ for $T \geq \frac{1}{A-\delta} \ln \left(\frac{\theta}{k_{0}}\right) \cdot{ }^{18}$ In particular, it declines from infinity towards 1 as $T$ increases from $\frac{1}{A-\delta} \ln \left(\frac{\theta}{k_{0}}\right)$. This guarantees that $(21)$ is sufficient for optimum.

In a closed economy with Ak technology and logarithmic preference, the domestic interest rate $r=A-\delta$. At this value of $r, \gamma=\gamma^{a}$ and $\Phi_{2}=\rho$ so that the right side of (21) is equal 1. But the left side is greater than 1 for any positive $\theta$ except when $T \rightarrow \infty$. This captures the notion that when the autarkic and world interest rate coincide, there is no benefit to entering the world capital market and it is never optimum to pay a fixed

\footnotetext{
${ }^{18}$ We thank an anomyous referee for the proof.
} 
entry cost to do so. Conversely, if (A2) is satisfied, i.e. $r<A-\delta$, the right side of the

inequality is greater than 1 . There is first a level effect which works through $\frac{\Phi_{2}}{\rho}>1$. And then there is a growth effect as $\gamma>\gamma^{a}$. Therefore in this case, there is always a finite entry date $T$ that satisfies (21) for any $k_{0}$ which is to say that eventual entry to the world capital market is optimum for any level of initial wealth given that $r<A-\delta$.

Specifically, for

$$
k_{0}>\theta \frac{\Psi}{\Psi-1} \equiv k^{d}
$$

where $\Psi$ denotes the right side of (21), the solution for $T$ from (21) as an equality is negative. This means that there is a minimum level of $k_{0}$ equal to $k^{d}$ as defined above at which immediate entry is optimum. Conversely if the household starts with initial physical capital below $k^{d}$, it will choose not to enter the world capital market immediately.

Finally, from $(22), k^{d}>\theta$, meaning that the threshold level of wealth that would induce the household to enter the world capital market is strictly greater than the minimum necessary. The household would not choose to enter once after it is technically feasible to do so. It prefers to enter only after passing this necessary minimum by an sufficient amount because of consumption smoothing.

\section{THE DYNAMICS OF OUTPUT AND LAND PRICE}

Does the phenomenon that land price grows faster than income signal speculative bubbles? Our analysis suggests that this needs not be the case. The growth rates of land price and income could diverge in a transition path of a perfect foresight equilibrium. While it is true that land price on the one hand and output and physical capital on the other hand must grow at the same constant rate $\gamma$ after the entry into the world capital market (c.f. eq. (13)), the behaviors of the two time paths before the entry is more intriguing. We can show that

Proposition 4 Before the entry to the international capital market, (a) Output and physical capital will grow at an increasing rate over time. 
(b) Land price and output cannot grow at the same rate. If land price grows at an increasing rate over time, it must grow at a faster rate than output and physical capital at each moment of time.

The key ingredient giving rise to part (b) is that the capital stock grows at an increasing rate. The appendix explains why in this case, it is impossible for land price to grow in proportion to physical capital. We would like to emphasis that the equilibrium that we analyze is a perfect foresight equilibrium that is free of any elements of speculative bubbles. Yet asset prices can grow faster than output and the stock of physical capital over the transition.

\section{RESPONSE TO SHOCKS}

In section 2, we present a canonical model of endogenous growth with international borrowing that shows faster steady state growth will result if the country has access to international borrowing at a sufficiently low interest rate. We now undertake to check the response of the economy to external shocks pertaining to conditions in the world capital market.

In particular, consider an economy that has been engaging in maximum leverage borrowing. Suppose at some time $t$, the world interest rate rises to some $r^{\prime}$ unexpectedly from the initial level $r$ for an interval of $\Delta t$. We ask what would happen to the paths for output, capital, consumption and land price?

The answer depends crucially on the terms of the country's external debt. The more empirically relevant case is that of short term debt as most developing countries' debt are indeed short term. ${ }^{19}$ Furthermore, the microeconomics underlying the borrowing constraint in (4), as explained in KM, calls for debt with the shortest possible term - one period in the discrete time model of theirs.

In fact, the effects of unexpected changes in conditions in the world capital market on

\footnotetext{
${ }^{19}$ For instance, see Calvo and Mendoza (1996), Cole and Kehoe (1996), Velasco and Chang (1988) and the reference therein.
} 
the domestic economy are most pronounced when the debt is of the shortest duration. Unexpected temporary increases in world interest rate would not have much of an effect on the cost of borrowing if most existing debt can be continuously serviced at the preshock interest rate. It is only the addition to existing borrowing which may be dearer to service if most of the country's external debt is long term debt. Conversely, if the debt is of a term $d t \simeq 0$ so that all debt matures in the next instant, all borrowing must be serviced at the higher post-shock interest rate.

More important is the effect on the amount that may be borrowed. Denote $k_{e}(\tau)$ as the household's equity in physical capital. By virtue of (7), the quantity of physical capital that the household may amass as a function of its equity is

$$
k(\tau)=\frac{1+r}{r+\delta} k_{e}(\tau)+\frac{1}{r+\delta} q(\tau)
$$

If the existing debt is yet to mature, the capital stock that the household may hold would not have to be adjusted even if the equity of the household may only strictly permit it to borrow a smaller amount at the higher interest rate. On the other hand, with existing debt maturing at every instant, the relationship in (23) would hold at all time when all existing debt are recalled and only a discretely smaller quantity of new loan would be extended at the higher interest rate. In particular, a small increase in interest rate could call for a dramatic downward adjustment in $k$. First the two multipliers $\frac{1+r}{r+\delta}$ and $\frac{1}{r+\delta}$ would be lowered. And then since $q$ is a function of $k$, the downward adjustment in $k$ would lower $q$ which by (23) would drag down $k$ further, leading to the onset of a downward spiral in asset prices, loans, physical capital and output.

To separate out the primary and secondary effects, assume hypothetically that following the unexpected interest rate shock, $q$ remains unchanged. Holding fixed land price $q$, the elasticity of the capital stock with respect to changes in world interest rate can be expressed $\mathrm{as}^{20}$

$$
\left|\frac{r}{k} \frac{\partial k}{\partial r}\right|_{q \text { fixed }}=\frac{r}{r+\delta} \frac{1-\delta}{1+r}+\frac{\alpha A r}{1+r}[(1+\rho)(r+\delta)-A(1+\alpha)]^{-1}
$$

\footnotetext{
${ }^{20}$ The derivations of $(24)$ and (25) to follow can be found in the appendix.
} 
Although land price is assumed fixed in the above derivation, it nevertheless contributes to the fluctuation because at the higher interest rate, the household's equity in land can only support a smaller quantity of loan. This effect works through the second term in the above. Of course, at $\alpha=0$, land has no role in production and its price $q=0$ and the effect vanishes. The first term in (24) may then be taken as the lower bound of the effect of the interest rate shock. Under the usual parameterization, even this lower bound is only slightly below 1 .

But the effect of $r$ on $k$ is still larger once we also consider the effect of $r$ on $q$ and the repercussions on leverage borrowing. From (23), it can be seen that evaluating the total effect calls for expressing $q$ as a multiple of $k_{e}$ and substituting the result back into the equation. The appendix shows that this yields

$$
k(\tau)=\frac{1+r}{r+\delta} \frac{(1+\rho)(r+\delta)-A}{(1+\rho)(r+\delta)-A(1+\alpha)} k_{e}(\tau)
$$

Eq. (25) is the reduced form expression relating the quantity of capital held by the household as a multiple of its own equity in physical capital. The total effect of $r$ on $k$, from differentiating the above is

$$
\left|\frac{r}{k} \frac{d k}{d r}\right|=\frac{r}{r+\delta} \frac{1-\delta}{1+r}+\frac{\alpha A r}{1+r}[(1+\rho)(r+\delta)-A(1+\alpha)]^{-1} \frac{1+\rho}{(1+\rho)(r+\delta)-A} .
$$

The difference between the above and the effect depicted in (24) is that the second term is augmented by the multiple $\frac{1+\rho}{(1+\rho)(r+\delta)-A}$ which could be a very large number. To see this, remember that from (A2), $A$ is bounded above $r+\delta$. Accordingly the term is bounded above $\frac{1+\rho}{(r+\delta) \rho}$ which is apparently a very large multiple. This means that even for fairly small values of $\alpha$, the effect of fluctuating land values on output and capital can be substantial. This underscores the point that the endogenous fluctuation in land values is an important propagating mechanism for output fluctuation when land is used as collateral for leverage borrowing.

It is possible to undertake a more exact analysis of how the economy responds to the positive interest rate shock. At time $t$, the instant after the increase in interest rate, there will be a discrete downward adjustment of capital stock as described above. This pins 
down the capital stock that remains at the instant just after $t$. If the shock is expected to last for an interval of $\Delta t$, the household's optimal response is the solution to

$$
\max _{x(\tau)}\left\{\int_{t}^{t+\Delta t} e^{-\rho(\tau-t)} \ln c(\tau) d \tau+e^{-\rho \Delta t} V_{I}\left(k^{+}(t+\Delta t)\right)\right\}
$$

subject to the $c(\tau)$ given in (9) with $r$ replaced by $r^{\prime}$, the two equations of motion given respectively in (2) and (3) and

$$
k^{+}(t+\Delta t)=\frac{\Omega(r)}{\Omega\left(r^{\prime}\right)} k^{-}(t+\Delta t)
$$

where $\Omega(r)=\frac{1+r}{r+\delta} \frac{(1+\rho)(r+\delta)-A}{(1+\rho)(r+\delta)-A(1+\alpha)}$.

To understand (27), first recall that the interest rate is expected to return to the original level $r$ at $t+\Delta t$. Just before so, from (25)

$$
k_{e}^{-}(t+\Delta t)=\Omega\left(r^{\prime}\right)^{-1} k^{-}(t+\Delta t)
$$

The condition in (27) follows once we recognize that the path for $k_{e}$ must be smooth. In the above, we assume that the post-shock interest rate $r^{\prime}$ is still below the user cost of capital $A-\delta$. Of course, this needs not be true. When the world interest rate rises above the $A-\delta$, all international borrowing comes to a halt. In this case, we modify the above by replacing $\Omega\left(r^{\prime}\right)^{-1}$ with 1 and use the budget constraint (15) instead of the budget constraint implied by $(9) \cdot{ }^{21}$

We may solve this problem by breaking it into two parts, much like the procedure we employ previously in solving for the optimal entry to international borrowing. In the first step, we solve for the optimal consumption path in the interval $(t, t+\Delta t)$ taking as given a fixed terminal capital stock $k^{-}(t+\Delta t)$. We can then calculate the sum of discounted utility for the interval $(t, t+\Delta t)$ with the consumption path just obtained. Together with the known closed form for $V_{I}$ given in (14), this enables us to arrive at a closed form expression for discounted lifetime utility at $t$ as a function of $k^{-}(t+\Delta t)$. Finally, discounted lifetime utility is maximized with respect to $k^{-}(t+\Delta t)$.

\footnotetext{
${ }^{21}$ Strictly speaking, the model implies that all domestic production should shut down in this case, with all resources lent to the outside world. For the sake of argument, we assume that the household's equity can not be sold in short notice to prevent this extreme prediction of the model.
} 
Following the procedure just sketched, it can be shown that ${ }^{22}$ during the episode of unexpectedly high interest rate, the growth rates of consumption, capital and output are all constant at $\gamma^{\prime}=\frac{1+r^{\prime}}{r^{\prime}+\delta} A-1-\rho .^{23}$ Since without the shock, the growth rate would have been $\gamma=\frac{1+r}{r+\delta} A-1-\rho$, the change in growth induced by the shock is

$$
\frac{\partial \gamma}{\partial r}=\frac{\delta-1}{(r+\delta)^{2}} A
$$

To see the approximate magnitude of the above, assume that the world interest rate $r$ is only slightly below $A-\delta$, then $\frac{\partial \gamma}{\partial r} \simeq \frac{\delta-1}{r+\delta}$. This could again be an extremely large negative number under the usual values for $r$ and $\delta$.

In all, the economy could be extremely vulnerable to unexpected changes in the world interest rate, in both level as reflected in the possible large decline in the level of physical capital just after the shock and in growth during the interval of high interest rate.

International borrowing can be thought of as the availability of a better technology with net marginal product of capital $\frac{1+r}{r+\delta} A-1$ which is greater than $A-\delta$ the net marginal product of capital in a closed economy for $r<A-\delta$. The unexpected increase in $r$ is analogous to a deterioration of the better technology. With logarithmic preference, we find that growth during the episode of low productivity (high interest rate), as well as in other times, is equal to $\frac{1+r}{r+\delta} A-1-\rho$ whatever $r$ turns out to be ${ }^{24}$. This result is sensitive to the assumption of logarithmic preference. "Lower productivity" during the episode of high interest rate does not lead to higher or lower rate of accumulation other than the adjustment called for by the change in "productivity" per se because intertemporal substitution and wealth effects exactly cancel under logarithmic preference. If intertemporal substitution is sufficiently strong, the household may want to slow down accumulation even further.

\footnotetext{
${ }^{22}$ The proof is available upon request.

${ }^{23}$ When $r^{\prime}>A-\delta$, all international borrowing would halt, $\gamma_{c}=\gamma_{c}^{a}$. This imposes an upper bound on how much growth can decline.

${ }^{24}$ With the exception when $r^{\prime}>A-\delta$ in which case the growth rate resorts to its autarkic level $\gamma^{a}=A-\delta-\rho$
} 


\section{CONCLUDING REMARKS}

Economic crises are often catalysts for sophisticated economic research. The Great Depression in 1930s has inspired generations of economists to develop new theories. Keynes (1936), Friedman and Schwartz (1963), Lucas (1972), among others, are all intellectual responses to it and they generate waves of dramatic changes in macroeconomics. Unfortunately, while the profession has yet to come up with a widely accepted interpretation of the Great Depression, there is another just as great a challenge to take up. It is the Asian crisis of 1997-98. When economists, and so as the general public, is debating whether the postwar economic performance of East Asia is just a myth or a true miracle, a sequence of seemingly small events triggers a sequence of collapses in several Asian countries. And even the most optimistic analysts will agree that the crisis is yet to be over.

Many papers have been written on this subject. We differentiate our efforts from others by focusing on the timing of the event. In particular, why would the crisis happen now but not any time before? It seems that a static coordination failure story cannot provide a satisfactory answer to that. In fact, empirical work suggests that there are very clear signs for crises and the growth of foreign lending is a robust one. This observation motivates a model which could generate significant output declines with a small change in the international capital market. However, a model as such is not satisfactory either. Previous studies point out that the development of finance helps promote growth through making the availability of credit easier. So the challenge is to reconcile these two strands of investigation in an unifying framework. The main theme of this paper is that financial development does improve growth by providing leverage, and yet it makes the local economy more vulnerable to small changes in conditions in the international capital market. Under the assumption of maximum leverage and with the usual parameterization, the

effect can be very significant. While we leave out many possible propagation mechanisms, the leverage effect alone is already overwhelming.

We want to emphasize that while the estimates of the effects of interest rate shocks presented in the last section are special to the model, the theme of our analysis holds 
in more general environment. In particular the assumption that the net marginal cost of capital in the domestic economy is perpetually above the world interest rate cannot be literally true. We could enrich our model by assuming that there is an initial range of decreasing returns, as in the model of Jones and Manuelli (1990). It would then be reasonable to assume that the world interest rate is equal to the long run marginal product of capital. In this model, the country only borrows in its transition to the constant growth equilibrium. The alternative model is much more clumsy to analyze but rewards few additional insights, except potentially better quantitative predictions.

Another apparent defect of our analysis is that we have not explicitly modelled uncertainty in the world interest rate. Upon a moment of reflection, it seems that the analysis would not have changed in any important ways though. When the debt is of duration $d t \simeq 0$, the country only borrows when $r<A-\delta$. It cannot be worse off and the average growth rate must be higher with international borrowing than without. And when $r$ rises above $A-\delta$, it simply stops borrowing. It is only when the country has to commit to long term debts with a fluctuating interest rate that there would be any change of substance in the analysis. 


\section{APPENDIX}

\section{PROOF OF PROPOSITION 1}

Solving the optimum control problem yields two Euler equations:

$$
\begin{aligned}
& \frac{\dot{c}(\tau)}{c(\tau)}=\frac{1+r}{r+\delta} A l(\tau)^{\alpha}-1-\rho, \\
& \frac{\dot{c}(\tau)}{c(\tau)}=\frac{1+r}{r}\left(\frac{1}{q(\tau)} \alpha A k(\tau) l(\tau)^{\alpha-1}+\frac{\dot{q}(\tau)}{q(\tau)}\right)-1-\rho .
\end{aligned}
$$

In equilibrium $l(\tau)=1$, the above simplify to

$$
\begin{aligned}
& \frac{\dot{c}(\tau)}{c(\tau)}=\frac{1+r}{r+\delta} A-1-\rho, \\
& \frac{\dot{c}(\tau)}{c(\tau)}=\frac{1+r}{r}\left(\alpha A \frac{k(\tau)}{q(\tau)}+\frac{\dot{q}(\tau)}{q(\tau)}\right)-1-\rho .
\end{aligned}
$$

Call the constant growth rate of consumption from (28) $\gamma$. It is easily shown that $\gamma$ exceeds $A-\delta-\rho$ if (A2) holds. And by (A1), positive consumption growth is assured.

Next, combine (28) and (29):

$$
\dot{q}(\tau)=A \frac{r}{r+\delta} q(\tau)-\alpha A k(\tau)
$$

Using (2), (3) and the fact that $i(\tau)=0$ in equilibrium, (9) becomes

$$
c(\tau)=\left(A-\frac{r+\delta}{1+r}\right) k(\tau)-\frac{r+\delta}{1+r} \dot{k}(\tau)+\frac{1}{1+r}(\dot{q}(\tau)-r q(\tau)) .
$$

Rearranging and substituting from (30)

$$
\dot{k}(\tau)=\left(A \frac{1+r-\alpha}{r+\delta}-1\right) k(\tau)-\frac{1+r}{r+\delta} c^{+}(T) e^{\gamma(\tau-T)}+\frac{r}{r+\delta}\left(\frac{A}{r+\delta}-1\right) q(\tau) .
$$

Note that in the above, we use $c^{+}(T)$ as the initial level of consumption instead of just $c(T)$ because the discontinuity in $k$ at $T$ might also induce a discontinuity in $c$.

Eqs. (30) and (31) are two linear differential equations in $k$ and $q$ that completely characterize the paths for physical capital and land price. It is easily verified that a constant growth path for $k$ and for $q$ is a solution to the system. Eq. (30) implies that in 
the constant growth equilibrium, $k$ and $q$ must grow at the same rate and the equation becomes

$$
\gamma_{k}=A \frac{r}{r+\delta}-\alpha A \frac{k(\tau)}{q(\tau)}
$$

where $\gamma_{k}$ is the growth rate of $k$. Eq. (31) implies that if $\frac{\dot{k}}{k}$ is constant and given that $\frac{k(\tau)}{q(\tau)}$ is also constant, $k$ and $c$ must grow at the same rate. Equating (32) to (28) yields (13). Now substitute (13) into (31)

$$
\dot{k}(\tau)=\left(\Phi_{0}+\gamma\right) k(\tau)-\frac{1+r}{r+\delta} c^{+}(T) e^{\gamma(\tau-T)}
$$

where

$$
\Phi_{0}=\rho+\frac{\alpha A}{(r+\delta)}\left[\frac{(A-r-\delta) r}{[(1+\rho)(r+\delta)-A]}-1\right]
$$

Eq. (33) is a linear differential equation in $k$ whose general solution takes the form:

$$
k(\tau)=\frac{1}{\Phi_{0}} \frac{1+r}{r+\delta} c^{+}(T) e^{\gamma(\tau-T)}+B e^{\left(\Phi_{1}+\gamma\right)(\tau-T)}
$$

where $B$ is the constant of integration. Since $k$ is always growing at $\gamma$, the constant $B$ must equal 0 . Then inverting the equation above

$$
c(\tau)=\Phi_{0} \frac{r+\delta}{1+r} k^{+}(T) e^{\gamma(\tau-T)} .
$$

The positivity of $\Phi_{0}$ is guaranteed by assumptions (A2), (A3a) and (A3b). ${ }^{25}$

To complete the solution for $c(\tau)$, we have to express $k^{+}(T)$ in terms of the given initial level of capital $k(T)=k_{T}$. To this end, apply (13) to (11). This yields the formula in part (a) of the proposition. Next substituting the result back to (35) yields the last formula in part (c).

\footnotetext{
${ }^{25}$ The proof is as follows. From (A2), the lower bound of $A$ is $r+\delta$. At this value of $A, \Phi_{0}=\rho-\alpha$. The second inequality in (A3b) assures that this is positive. Differentiate $\Phi_{0}$ with respect to $A$ yields an expression proportional to

$$
\frac{\partial \Phi_{0}}{\partial A} \propto r(A-r-\delta)\left[1+\frac{A}{(1+\rho)(r+\delta)-A}\right]+[A(1+r)-(1+\rho)(r+\delta)] .
$$

The positivity of the first term is guaranteed by (A2) and (A3a). The second term is also positive by (A2) and the first inequality in (A3b).
} 


\section{PROOF OF PROPOSITION 2}

For each $\tau \leq T$, the necessary conditions for maximizing (16) are:

$$
\begin{aligned}
& \frac{\dot{c}(\tau)}{c(\tau)}=A l(\tau)^{\alpha}-\delta-\rho, \\
& \frac{\dot{c}(\tau)}{c(\tau)}=\alpha A \frac{k(\tau) l(\tau)^{\alpha-1}}{q(\tau)}-\rho+\frac{\dot{q}(\tau)}{q(\tau)} .
\end{aligned}
$$

In equilibrium, $l(\tau)=1$, the above reduce to

$$
\begin{aligned}
& \frac{\dot{c}(\tau)}{c(\tau)}=A-\delta-\rho, \\
& \frac{\dot{c}(\tau)}{c(\tau)}=\alpha A \frac{k(\tau)}{q(\tau)}-\rho+\frac{\dot{q}(\tau)}{q(\tau)} .
\end{aligned}
$$

The first one is the familiar constant consumption growth condition in Ak endogenous growth model. The second condition is from maximizing with respect to $x_{l}(\tau)$. Since in equilibrium, $x_{l}(\tau)=0$ as the supply of land is fixed, the condition is actually spurious in that it doesn't affect allocation but only helps pin down $q(\tau)$ once the path for $k(\tau)$ becomes known.

In characterizing the equilibrium, we note that constant consumption growth and the fact that $x_{l}(\tau)=0$ allows rewriting the budget constraint in (15) as

$$
\dot{k}(\tau)=(A-\delta) k(\tau)-c(0) e^{\gamma^{a} \tau}
$$

where $\gamma^{a}$ is the growth rate of consumption as defined in (36). Solving this differential equation yields (17) in part (b) of the proposition. The two constants $c(0)$ and $B$ can be fixed with the help of the initial and boundary conditions : $k(0)=k_{0}$ and $k(T)=k^{*}$ :

$$
\begin{aligned}
c(0) & =\rho \frac{k_{0}-e^{-(A-\delta) T} k^{*}}{1-e^{-\rho T}}, \\
B & =\frac{e^{-(A-\delta) T} k^{*}-e^{-\rho T} k_{0}}{1-e^{-\rho T}} .
\end{aligned}
$$

\section{PROOF OF PROPOSITION 3}

Maximizing (19) with respect to $k^{*}$ yields

$$
-\left(\frac{1-e^{-\rho T}}{e^{(A-\delta) T} k_{0}-k^{*}}\right)+\frac{e^{-\rho T}}{k^{*}-\theta}=0 .
$$


Differentiating the left side further verifies that the second order condition is met for each $T \geq 0$. Hence the above is also sufficient for optimum at given $T$. Solving for $k^{*}$ yields (20). The necessary condition for optimum $T$ is

$$
\begin{gathered}
\rho e^{-\rho T}\left\{\ln c(0)+\frac{\gamma^{a}}{\rho}\right\}+\left(1-e^{-\rho T}\right) \frac{1}{c(0)} \frac{\partial c(0)}{\partial T}+\rho \gamma^{a} e^{-\rho T} T-\gamma^{a} e^{-\rho T}- \\
\rho e^{-\rho T}\left\{\ln \left(k^{*}-\theta\right)+\ln \Phi_{2}+\frac{\gamma}{\rho}\right\} \leq 0
\end{gathered}
$$

with equality if $T>(A-\delta)^{-1} \ln \left(\theta / k_{0}\right)$. Eq. (21) is obtained from substituting (20) into the above.

\section{PROOF OF PROPOSITION 4}

First apply (20) to (17)

$$
k(\tau)=k_{0} e^{(A-\delta-\rho) \tau}\left[e^{\rho \tau}+\left(e^{\rho \tau}-1\right) \Theta\left(k_{0}, T\right)\right]
$$

where

$$
\Theta\left(k_{0}, T\right)=1-\frac{\theta}{k_{0} e^{(A-\delta) T}} \in(0,1) .
$$

This is an expression relating the time path for $k(\tau), \tau<T$ to the initial capital stock and the date of transition $T$. The restriction that $\Theta\left(k_{0}, T\right)$ lies in the unit interval is from the fact that the optimum entry date $T$ must obey $k_{0} e^{(A-\delta) T}>\theta$. The growth rate of $k$ during the transition is therefore

$$
\frac{k \dot{k}(\tau)}{k(\tau)}=A-\delta-\rho+\rho \frac{1-\Theta\left(k_{0}, T\right)}{1-\left(1-e^{-\rho \tau}\right) \Theta\left(k_{0}, T\right)}
$$

which is an increasing function of $\tau$ given that $\Theta\left(k_{0}, T\right) \in(0,1)$.

The behavior of land price in the transition is governed by (37). Using (36) and rearranging

$$
\frac{\dot{q}(\tau)}{q(\tau)}=A-\delta-\alpha A \frac{k(\tau)}{q(\tau)} .
$$

The fact that $k$ is growing at a non-constant rate implies that $k$ and $q$ cannot grow at the same rate. If they did, (41) says that $\frac{\dot{q}(\tau)}{q(\tau)}$ would be constant. But then $\frac{k(\tau)}{k(\tau)}$ is not. 
To compare the growth rates of output and land price, we substitute (40) into (41) and solve the resulting differential equation in $q$

$$
q(\tau)=e^{(A-\delta-\rho) \tau}\left[\frac{\alpha A}{\rho}\left(k_{0}-\theta e^{-(A-\delta) T}\right)+\left(B-\alpha A \theta e^{-(A-\delta) T}\right) e^{\rho \tau}\right]
$$

To pin down the constant of integration $B$, we use a terminal condition that the above must satisfy. Since $q$ can not experience any discontinuity, $q(T)=q^{+}(T)$ and the latter can be recovered from (13), part (a) of proposition 1, (20) and the fact that $k_{T}=k^{*}-\theta$

$$
q(T)=e^{(A-\delta-\rho) T} \frac{\left(k_{0}-\theta e^{-(A-\delta) T}\right)(1+r) \alpha A}{(1+\rho)(r+\delta)-A(1+\alpha)} .
$$

Now $B$ can be found by equating the above to (42) evaluated at $T$. Substitute the result back into (42), we have

$$
\begin{aligned}
q(\tau)= & \frac{\alpha A}{\rho}\left(k_{0}-\theta e^{-(A-\delta) T}\right) e^{(A-\delta-\rho) \tau} \times \\
& \left(1+e^{\rho(\tau-T)}\left\{\frac{\rho(1+r)}{(1+\rho)(1+\delta)-A(1+\alpha)}-1\right\}\right)
\end{aligned}
$$

The growth rate of $q$ is increasing if the terms inside the curly bracket are positive and negative otherwise.

It is generally impossible to determine whether $k$ and therefore output or $q$ grows faster in the transition. Suppose the terms inside the curly bracket are positive, so that $q$ grows at an increasing rate. If so (41) implies that the fraction $\frac{k}{q}$ must decline over time.

\section{THE DERIVATIONS OF EQS. (24) AND (25)}

From (23), the effect on $k$ holding $q$ constant is

$$
\left|\frac{r}{k} \frac{\partial k}{\partial r}\right|_{q \text { fixed }}=\frac{r}{r+\delta} \frac{(1-\delta) k_{e}(\tau)+q(\tau)}{(1+r) k_{e}(\tau)+q(\tau)} .
$$

To evaluate the magnitude of the above, it is necessary to express $q$ in terms of $k_{e}$. This can be done by substituting (23) into (13) and solving the resulting equation for $q$

$$
q(\tau)=\frac{\alpha A(1+r)}{(1+\rho)(r+\delta)-A(1+\alpha)} k_{e}(\tau) .
$$

Plugging the above back to (44) yields (24). To obtain (25), simply substitute the above into (23). 


\section{REFERENCES}

[1] Bencivenga, Valerie R.and Bruce Smith, "Financial Intermediation and Endogenous Growth," Review of Economic Studies; 58 (1991):195-209.

[2] Boyd John H. and Bruce Smith, "Capital Market Imperfections, International credit markets, and nonconvergence," Journal of Economic Theory, 73 (1997):335-64.

[3] Calvo, Guillermo and Enrique Mendoza, "Mexico's Balance-of-Payments Crisis: a Chronicle of a Death Foretold," Journal of International Economics, 41 (1996):235-264.

[4] Cole, Harold and Timothy Kehoe, "A Self-Fulfilling Model of Mexico's 1994-1995 Debt Crisis," Journal of International Economics, 41 (1996):309-330.

[5] Devereux, Michael, "A Tale of Two Currencies: The Asian Crisis and the Exchange Rate Regimes of Hong Kong and Singapore," manuscript, University of British Columbia, 1998.

[6] Frankel, Jeffrey and Andrew Rose, "Currency Crashes in Emerging Markets: an Empirical Treatment," Journal of International Economics, 41 (1996):351-366.

[7] Friedman, Milton and Anna Schwartz, A Monetary History of the United States, 18671960, Princeton: Princeton University Press, 1963.

[8] Greenwood, Jeremy and Boyan Jovanovic, "Financial Development, Growth, and the Distribution of Income," Journal of Political Economy, 98 (1990):1076-1107.

[9] Jones Larry E. and Rodolfo E. Manuelli, "A Convex Model of Equilibrium Growth: Theory and Policy Implications," Journal of Political Economy, 98 (1990):1008-1038.

[10] Keynes, John Maynard, The General Theory of Employment, Interest and Money, London: Macmillan, 1936.

[11] King, Robert G. and Ross Levine, "Finance and Growth: Schumpeter Might Be Right," Quarterly Journal of Economics, 108 (1992):717-37. 
[12] Kiyotaki, Nobuhiro and John Moore, "Credit Cycles," Journal of Political Economy, 105 (1997):211-248.

[13] Kiyotaki, Nobuhiro, "Credit and Business Cycles," Japanese Economic Review, 49 (1998):18-35.

[14] Lee, Jong-Wha and Yong Jin Kim, "Over-investment, Collateral Lending, and Economic Crisis," manuscript, Korea University, 1998.

[15] Levine, Ross, "Financial Development and Economic Growth: Views and Agenda," Journal of Economic Literature, 35 (1997):688-726.

[16] Levine, Ross and Sara Zervos, "Stock Markets, Banks, and Economic Growth," American Economic Review, 88 (1998):537-558.

[17] Long, Ngo Van and Kar-yiu Wong, "Endogenous Growth and International Trade: a Survey," in Bjarne Jensen and Kar-yiu Wong (ed.), Dynamics, Economic Growth, and International Trade, Ann Arbor: University of Michigan Press, 1997.

[18] Lucas, Robert, "Expectations and the Neutrality of Money," Journal of Economic Theory, 4 (1972):103-124.

[19] Obstfeld, Maurice and Kenneth Rogoff, Foundations of International Macroeconomics, Cambridge: MIT press, 1996.

[20] Otker, Inci and Ceyla Pazarbasioglu, "Speculative Attacks and Macroeconomic Fundamentals: Evidence from Some European Currencies," European Economic Review, 41 (1997):847-860.

[21] Rebelo, Sergio, "Long-Run Policy Analysis and Long-Run Growth," Journal of Political Economy, 99 (1991):500-521.

[22] Turnovsky, Stephen, "Endogenous Growth in a Dependent Economy with Traded and Nontraded Capital," Review of International Economics, 4 (1996):300-321. 
[23] Turnovsky, Stephen, International Macroeconomic Dynamics, Cambridge: MIT Press, 1997.

[24] Turnovsky, Stephen and Pradip Chattopadhyay, "Volatility and Growth in Developing Economies: Some Numerical Results and Empirical Evidence," manuscript, University of Washington, Seattle, 1998.

[25] Turnovsky, Stephen and Partha Sen, "Investment in a Two-Sector Dependent Economy," Journal of the Japanese and International Economies, 9 (1995):29-55.

[26] Velasco, Andres and Roberto Chang, "The Asian Liquidity Crisis," New York University, manuscript, 1998.

[27] Wong, Kar-Yiu (ed.), The Asian Crisis: what has happened and why?, manuscript, University of Washington, Seattle, 1998. 